\title{
TRIBUNAL SUPREMO Y CAMBIOS EN EL FEDERALISMO DE ESTADOS UNIDOS*
}

\author{
JOSEP M. ${ }^{a}$ CASTELLÁ ANDREU \\ Profesor titular de Derecho Constitucional \\ Universidad de Barcelona
}

SuMARIO

I. El Tribunal Rehnquist: una nueva etapa en la historia del Federalismo americano.

II. Una relectura restrictiva de la cláusula de comercio interestatal.

III. La revalorización de la X Enmienda.

IV. La doctrina de la inmunidad de los estados: la expansión de la XI Enmienda y la restrictiva aplicación del apartado 5 de la XIV Enmienda.

V. La doctrina de la prevalencia del derecho federal sobre el estatal (preemption).

VI. Perspectivas de futuro.

\section{EL TRIBUNAL REHNQUIST: UNA NUEVA ETAPA EN LA HISTORIA DEL FEDERALISMO AMERICANO}

El Federalismo forma parte esencial del pacto constitucional alcanzado por la Convención de Filadelfia en 1787 y que dio origen a la Nación americana. De hecho estamos ante la más prolongada experiencia federal contemporánea, que, no por casualidad, se ha convertido en arquetipo de la forma de estado federal ${ }^{1}$, al menos del Estado federal de agregación o clásico. En

* Este trabajo forma parte de una investigación más amplia llevada a cabo en la School of Law del Boston College durante el primer semestre de 2009 gracias a una beca concedida por el Institut d' Estudis Autonòmics de la Generalitat de Catalunya. Agradezo a los profesores Gregory Kalscheur y a Gail Hupper las atenciones recibidas durante mi estancia en Boston.

1 Así por ejemplo K. C. WHEARE en Federal Government, traducido al catalán por el IEA en 2008 en una nueva y muy cuidada colección de los clásicos del federalismo. Dejamos de lado 
el largo periodo de tiempo que va desde 1787 hasta nuestros días, el federalismo americano ha pasado por etapas muy variadas que han contribuido a configurar un modelo de estado, solo en parte asimilable al primigenio diseñado por la Constitución. Este carácter evolutivo del federalismo americano se compagina con la evocación permanente del momento fundacional, que siempre ha actuado para los distintos intérpretes constitucionales como parámetro de contraste respecto de las modificaciones que se han ido introduciendo, ya sea para denunciar el distanciamiento respecto del modelo original, ya sea para justificar las alteraciones debidas a los cambios de contexto de cada momento histórico. La tensión entre la fidelidad a los orígenes del Estado federal —el dual federalism y el poder soberano de los estados- y la necesaria adaptación a las cambiantes circunstancias sociales, económicas y políticas - ya fuese la guerra civil, la crisis económica de los años treinta del siglo veinte, o la lucha a favor de los derechos civiles en los cincuenta y sesenta, por citar los hitos más significativos - ha marcado la trayectoria seguida por la división vertical del poder a lo largo de la historia contemporánea de Estados Unidos.

Aunque en algunas ocasiones se ha seguido el procedimiento de reforma constitucional (art. V) para abordar algunos de los cambios que han incidido en la historia del federalismo - merecen destacarse las conocidas como "Enmiendas de la Guerra" (las XIII, XIV y XV de 1865, 1868 y 1870 respectivamente, que autorizan al Congreso a hacer valer los derechos individuales que regula frente a los estados) y otras posteriores (como la XVII, sobre la elección directa de los senadores en 1913) —, lo cierto es que ha sido el Tribunal Supremo el que ha jugado en todo momento un papel capital en la interpretación de las cláusulas constitucionales y, por tanto, en la progresiva evolución del federalismo (desde McCulloch $v$. Maryland en 1919). Especial mención merecen las sentencias que en los años del New Deal acabaron con la interpretación tradicional del federalismo dual y legitimaron una amplia intervención centralizadora de las autoridades federales en la política social y económica². De ahí el interés que merece el seguimiento de la jurisprudencia del Alto Tribunal federal, en particular la de las

otras experiencias históricas que han sido calificadas a veces como federales a pesar de que su origen y caracteres respondan a parámetros ajenos a los propios del Estado liberal democrático y de la constitución racional normativa (II Reich alemán, Imperio Austro Húngaro). Tampoco podemos entrar ahora en la cuestión de las diferencias entre el modelo federal clásico y los nuevos federalismos, fruto de procesos descentralizadores, que hacen inaplicables a estos algunos de los rasgos de los primeros.

2 Así National Labor Relations Board v. Jones \& Laughlin Steel Corp. [301 US 1 (1937)], United States v. Darby [312 US 667 (1941)], y Wickard v. Filburn [317 US 111 (1942)]. Estas sentencias dieron una interpretación amplia a la cláusula de comercio interestatal que legitima la legislación del Congreso en ámbitos relevantes de la vida social y económica. Así, el primer caso lleva a incluir en el ámbito de cobertura de dicha cláusula al negocio de acero y a las relaciones laborales suscitadas en su seno; el segundo afecta al transporte de mercancías y cómo ha de incluirse también en el comercio interestatal la propia producción de las mismas; el tercero, por último, aplicaba la cláusula a la producción de trigo reservada para consumo propio. 
dos últimas décadas, que ha propiciado la, por el momento, última etapa del federalismo americano.

Transcurridos más de doscientos veinte años desde el pacto federal es oportuno preguntarse por el estado actual del federalismo y por las transformaciones que ha vivido en las últimas décadas. Como en el pasado, conviene tener presente la relación entre los cambios políticos vividos por la sociedad americana, sobre todo desde la victoria del Presidente Reagan en 1980, y la modificación de la jurisprudencia del Tribunal Supremo. Vamos a centrar nuestra atención en el conocido como "Tribunal Rehnquist", esto es, en las líneas fundamentales que desde los años noventa del siglo XX ha seguido el Tribunal Supremo 3 . Se ha hablado de este periodo como de una "Revolución en el federalismo", para connotar los profundos cambios que se han producido en la forma de entender el federalismo y los denominados derechos de los estados. Dichos cambios han llegado al punto que el Tribunal ha vuelto a utilizar la olvidada expresión dual federalism ${ }^{4}$.

Esta revolución habría significado, en opinión de una buena parte de analistas, la alteración de las pautas interpretativas sobre las que se había asentado el federalismo desde finales de los años treinta, bajo el impulso del presidente Franklin D. Roosevelt. Desde entonces, y por más de sesenta años sin apenas excepción, el Tribunal Supremo siguió una línea jurisprudencial, aparentemente contradictoria, por la que, por una parte, el principio federal no era utilizado como límite al poder legislativo federal, dejando en consecuencia un amplio margen de actuación a las leyes del Congreso para intervenir en materias de competencia estatal (los denominados derechos de los estados). A la vez, por otra parte, el federalismo sí actuaba como límite al poder judicial federal, de modo que el Tribunal Supremo ejercía un control exigente sobre la intervención de los tribunales federales en ámbitos propios de la jurisdicción de los tribunales estatales 5 .

La nueva concepción del federalismo que se ha abierto paso, sobre todo a partir de los años noventa, ha consistido en la utilización del principio federal como límite tanto al poder legislativo como al poder judicial federales. Ello ha entrañado, sobre todo, una relectura del alcance: a) de la cláusula de comercio interestatal que ha consentido al Tribunal Supremo

3 William Rehnquist fue presidente del Tribunal entre 1986 y 2005 . Había llegado al Tribunal en 1972. Desde 2005, John Roberts ocupa la Presidencia, pero por el momento no se puede hablar de alteraciones profundas en la doctrina que sobre el federalismo fue elaborándose durante el periodo precedente. Ello es debido fundamentalmente a que no se ha modificado la correlación de fuerzas en el seno de la institución.

$4 \mathrm{El}$ primero en hacerlo fue el juez Scalia en nombre de la mayoría en Printz $v$. United States [521 US 898, 918 (1997)].

5 Esta paradoja, que supone una diferente interpretación del alcance de la X y la XI Enmiendas, ya fue denunciada en 1985 por J. BROWN en "State Sovereignty under the Burger Court - How the Eleventh Amendment Survived the Death of the Tenth: Some Broader Implications of Atascadero State Hospital v. Scanlon", Georgia Law Journal, núm. 74, 1985, pág. 363 ss. También se ha referido a ella más recientemente E. CHEMERINSKY, Enhancing Government.Federalism for the 21th Century, Stanford University Press, Stanford, 2008, pág. 15 
entrar a juzgar sobre el ejercicio que el Congreso hace de sus propias competencias; b) de la X Enmienda en el sentido de limitar la actuación del Congreso en relación con las competencias de los estados; y c) del apartado 5 de la XIV Enmienda restringiendo el campo de intervención de las leyes federales sobre los derechos constitucionales. Tales cambios jurisprudenciales han tendido a proteger los derechos de los estados frente a la actuación invasiva de las autoridades federales. Al mismo tiempo, y en aparente contradicción con la línea que se acaba de apuntar, la misma mayoría del Tribunal ha interpretado de forma amplia la doctrina de la preemption (o primacía o prevalencia) del derecho federal sobre el estatal, lo que ha supuesto la aplicación de normas federales en lugar de la legislación estatal en ámbitos relevantes de la actividad económica.

La "revolución federal" producida en las últimas décadas de la mano del Tribunal Rehnquist supone el triunfo de las tesis "federalistas" defendidas por los conservadores americanos, frente a la visión "nacionalista" que suele atribuirse a los demócratas. El Presidente Reagan ya aludió en los años ochenta al advenimiento de un "nuevo federalismo" que reconocía espacios más amplios de decisión a los estados. Y en 1994 esta visión del federalismo formó parte destacada del "Contrato con América" que suscribieron los congresistas de la mayoría republicana bajo el liderazgo de Newt Gingrich durante la presidencia Clinton.

Sobre el carácter controvertido de esta revolución federal impulsada por el Tribunal Supremo da cuenta la profunda división del propio Tribunal sobre el asunto, pues las sentencias sobre las que se apoya se han aprobado por una ajustada mayoría de 5 a 4 . Siendo así que los jueces conservadores de la mayoría han hecho valer su concepción del federalismo en el seno del Tribu$\mathrm{nal}^{6}$. La doctrina ha polemizado sobre si el enfrentamiento entre mayoría y minoría en el seno del Tribunal supone la confrontación entre un modelo

6 Nos referimos a los jueces William Rehnquist (nombrado a propuesta del presidente Nixon), Antonin Scalia, Sandra Day O'Connor, Anthony Kennedy (nombrados por el presidente Reagan) y Clarence Thomas (nombrado por el presidente George W.H. Bush). Posteriormente, el presidente George W. Bush nombró a John Roberts (2005) y a Samuel Alito (2006), que substituyeron a Rehnquist y O'Connor. Por tanto, se mantiene la misma mayoría de 5-4. En cambio, han presentado votos particulares a las sentencias más significativas de esta concepción del federalismo los jueces John Paul Stevens (nombrado por el presidente Ford), David Souter (nombrado por el presidente George W.H. Bush), Ruth Bader Ginsburg y Stephen Breyer (ambos nombrados por el presidente Clinton). Así pues, el nombramiento de Sonia Sotomayor a propuesta del presidente Obama en 2009, que substituye a Souter, en principio, no supone una alteración de mayorías en el Tribunal. Sobre las diferentes sensibilidades en el seno del Tribunal e incluso entre los jueces conservadores, entre viejos o moderados (O'Connor y Kennedy) y nuevos republicanos (el resto) es muy útil el libro de M. TUSHNET, The Rehnquist Court and the future of Constitutional Law, WW Norton, 2005. En opinión del autor, en temas sobre federalismo, todos los jueces conservadores habrían mantenido una unidad sustancial de criterio que, en cambio, no se ha dado en temas sociales y morales, si bien los "viejos conservadores" habrían impedido cambios más radicales en la orientación del nuevo federalismo. Adviértase que, en la actualidad, el juez Kennedy posee el quinto voto necesario para formar la mayoría. 
"federalista" o "pro estados" y otro "nacionalista " ${ }^{7}$ o si más bien debe interpretarse como pugna entre dos visiones distintas del federalismo. Así, los jueces conservadores pondrían el énfasis en la defensa de la "soberanía de los estados", entendida como el refuerzo del control judicial de la constitucionalidad de la actuación de las autoridades federales (cláusula de comercio interestatal, X Enmienda) y en la protección de la inmunidad jurisdiccional de los estados frente a la actuación judicial federal. En cambio, los jueces liberal se han opuesto a la imposición de límites constitucionales a la actuación federal pero, sin embargo, habrían subrayado la "autonomía de los estados", más orientada a salvaguardar la capacidad de decisión de las autoridades políticas estatales en áreas típicas propias de los estados frente al uso generoso de la preemption del derecho federal sobre el estatal llevada a cabo por la mayoría conservadora ${ }^{8}$.

Asimismo, se ha discutido la profundidad y la continuidad de la revolución federal conservadora ${ }^{9}$, así como la relación entre la agenda política conservadora en temas de modelo de sociedad (aborto, pena de muerte, uso de armas, desregulación) y la defensa de una concepción fuerte del federalismo. Dicho de otro modo, se ha cuestionado - lo que tampoco es nuevo en la historia constitucional y política de Estados Unidos - si la apuesta por el federalismo desde filas conservadoras obedece a cuestiones tácticas o instrumentales al servicio de la defensa de posiciones ideológicas de fondo, y que actúa como barrera a la extensión de determinados derechos civiles, o si dicha defensa responde más bien a criterios más profundos. En particular, la apuesta por el federalismo, por parte de los conservadores, serviría a dos razones de orden metodológico: primero, a la idea (expresada por el Juez Brandeis en 1932 y clásica en el federalismo americano) de que los estados son laboratorios adecuados para la experimentación política y social, y que la consiguiente generalización de las políticas que han sido probadas a ámbitos más extensos tendría lugar en caso de producir resultados positivos. Segundo, los estados actuarían como guardianes de la libertad individual y, por tanto, constituirían barreras a la "tiranía centralista" ${ }^{10}$. En cualquier caso, una

7 Apoya esta idea basándose en un estudio empírico de los casos, P. M. Jr. COLliNS, «Towards an Integrated mode of the US Supreme Court's Federalism Decisión making", Publius, núm. 37, 2007, pág. 15. El autor pronostica el mantenimiento de la revolución en los próximos años.

8 E. A. YOUNG, "The Rehnquist Court's two federalisms", Texas Law Review, núm. 83, 2004, pág. 6 ss. Dicho autor considera insuficientes ambas aproximaciones al tiempo que matiza el alcance de la supuesta revolución del Tribunal Rehnquist.

9 Para Steven G. CALABRESI, "Federalism and the Rehnquist Court: a normative defense", $A n$ nals of the American Academy of Political and Social Science, núm. 574, 2001, págs. 25 y 33, se trata de un verdadero cambio revolucionario, si bien considera que es un "correctivo leve" a medio siglo de expansión del poder nacional. Le atribuye un papel de símbolo, pero reconoce que el cambio es demasiado pequeño para reforzar el federalismo. Para E. RUBIN y M. FEELEY, "Federalism: some notes on a National Neurosis", UCLA Law Review, núm. 41, 1994, pág. 903 ss., consideran que se trata de un "puppy federalism", porque es demasiado suave.

10 A favor de la posición táctica de los conservadores en torno al federalismo se puede ver P. J. SMITH, "Federalism, Instrumentalism and the Legacy of the Rehnquist Court"; en cambio 
cosa parece indiscutible en Estados Unidos: la argumentación de las posiciones políticas conservadoras se ha hecho a lo largo de estos años, como en los precedentes, con base a criterios de constitucionalidad. El debate político no ha dejado de lado para nada el debate constitucional ${ }^{11}$.

Paradójicamente, la actuación pro estados de los jueces conservadores, normalmente partidarios de la neutralidad de los tribunales y del respeto a las decisiones políticas adoptadas por las instituciones de gobierno, habría incurrido en un notable activismo judicial, con la anulación de una cuarentena de leyes durante la presidencia de Rehnquist. Ello les ha supuesto la acusación, por parte de algunos autores, de haber llevado a cabo una fuerte intervención al servicio de un programa político y jurídico bien definido ${ }^{12}$.

\section{UNA RELECTURA RESTRICTIVA DE LA CLÁUSULA DE COMERCIO INTERESTATAL}

Desde 1936 hasta 1995, la cláusula de comercio entre estados (art. 1.8.3 de la Constitución Federal) ${ }^{13}$ no había sido utilizada por el Tribunal Supremo para declarar la inconstitucionalidad de ninguna ley federal impugnada. Por tanto, la cláusula era interpretada de forma que no establecía límites a la legislación aprobada por el Congreso sobre comercio entre estados. Cualquier actividad acababa teniendo, para el Tribunal, alguna relación con el comercio interestatal. Tal interpretación de la cláusula permitió al Congreso entrar a legislar sobre aspectos muy variados de la vida social y económica, aunque directamente se limitaran al interior de un estado ${ }^{14}$. Ello abarcaba derechos civiles, derecho antidiscriminatorio, derecho penal, la creación de agencias administrativas independientes o la protección del medio ambiente.

sostiene la postura contraria E.A. YOUNG, "The Conservative case for Federalism", ambos textos en el volumen que recopila los textos del "Symposium on the legacy of Rehnquist Court" de la George Washington Law Review, núm. 74, 2006, respectivamente pág. 906 ss. y pág. 874 ss. Young apuesta por un conservadurismo de corte metodológico que lleva a favorecer el federalismo, y que sería el seguido habitualmente por el Tribunal, frente a un conservadurismo político de fines, no siempre desarrollado por el Tribunal.

11 P. BERKOVITZ, "Constitutional Conservatism", Real Clear Politics, 2 febrero 2009, pág. 10. Muchos autores coinciden en señalar la decisión Brown v. Board of Education de 1954 como el punto de partida de esta tendencia, ver últimamente: J. E. LOWNDES, From New Deal to the New Right: Race and the Southern Origins of Modern Conservatism, Yale University Press, New Haven, 2008, pág. 29.

12 Lo pone de manifiesto M. TUSHNET, The Rehnquist Court and the future of Constitutional Law, cit. En sentido contrario, para G. CALABRESI, "Federalism and the Rehnquist Court: a normative defense", cit, pág. 35, las sentencias sobre las que se apoya la idea de la revolución federal no suponen detraer poder a las autoridades políticas por parte de los jueces, sino solo a las autoridades federales para atribuirlo a las estatales.

13 «El Congreso tendrá facultad (...) 3. Para reglamentar el comercio con las naciones extranjeras, entre los diferentes Estados y con las tribus indias" (se usa básicamente la traducción de Textos Constitucionales, EUB, Barcelona, 1997).

14 Nos remitimos a los casos enumerados en la nota núm. 2. 
El cambio jurisprudencial se produce en 1995 con United States v. Lopez ${ }^{15}$ al declarar inconstitucional (por 5-4) la Gun-Free School Zones Act. Dicha ley federal de 1990 establecía como nuevo delito federal la posesión de un revólver a menos de 1000 pies de un colegio. Para el Tribunal, la incidencia de esta concreta materia sobre la cláusula de comercio interestatal era marginal y no tenía relación "sustancial" con la misma. El presidente Rehnquist argumentó que, de acuerdo con la Constitución, los poderes del Congreso y del Gobierno federales son tasados, y solo pueden legislar si tiene competencia expresa o tácita. De este modo se estaba poniendo freno a la expansión del derecho penal federal, tan frecuente hasta entonces, en ámbitos que tradicionalmente habían sido regulados por los estados. Se trataba de una vuelta a la doctrina tradicional, anterior a los años treinta. El Tribunal estableció un "test" para verificar los tipos de actividades que incluye la protección de la cláusula de comercio interestatal: 1) el Congreso puede regular el uso de vías o cauces para el comercio interestatal (channels); 2) puede legislar y proteger los instrumentos o medios para dicho comercio (instrumentalities); y 3) puede regular las actividades que tengan una "relación substancial" con el comercio interestatal, abogando por una interpretación restrictiva de dicha afectación sustancial ${ }^{16}$. El voto particular de los 4 jueces discrepantes, redactado por el juez Breyer, acusó a la mayoría de "activismo judicial", condenó el abandono de la doctrina precedente y justificó la relación entre la prohibición federal y su impacto en la economía.

En otro caso de 2000, United States v. Morrison ${ }^{17}$, el Tribunal declaró la inconstitucionalidad de la Violence Against Women Act, en la que se autoriza a las víctimas de actos de violencia de género a reclamar por perjuicios económicos. El Congreso había legislado sobre el asunto porque, en su opinión, la legislación de los estados era insuficiente. Para el Tribunal (por 5-4), el Congreso no es competente para legislar sobre la violencia de género ni con base a la cláusula de comercio interestatal ni alegando el apartado 5 de la XIV Enmienda, pues corresponde a los estados la competencia sobre esta cuestión. En este caso, no se está produciendo por parte de los estados una violación de los derechos contenidos en el apartado 1 de la XIV Enmienda, único supuesto que permitiría al Congreso legislar para adoptar remedios, basándose en el apartado 5 de la XIV Enmienda ${ }^{18}$. Respecto a la cláusula de comercio interestsatal, la mayoría aplicó el test establecido en Lopez y consideró que el supuesto de hecho no se subsumía dentro del tercer criterio visto pues no quedaba demostrado que la violencia contra las mujeres tuviera "efectos sus-

15514 US 549 (1995). El demandante, Alfonso López, era un estudiante de una escuela superior de San Antonio (Texas) que había sido arrestado por llevar un arma de fuego con balas y condenado a 6 meses de cárcel y a 2 años de libertad condicional.

16 Este último supuesto es incluso rechazado por el voto concurrente del juez Thomas.

17529 US 598 (2000). El recurso lo plantea una mujer violada contra unos futbolistas de un equipo universitario que no habían sido juzgados penalmente ni sancionados por la Universidad, y contra la Universidad en un proceso civil por daños.

18 Sobre esta cuestión se volverá en el apartado IV. 
tanciales" en la economía, y que se trata de una materia de competencia estatal. Para Rehnquist, en lo que es el meollo de la cuestión, "No porque el Congreso concluya que una actividad particular afecta substancialmente al comercio interestatal necesariamente lo hace". De aplicarse el criterio contrario, cualquier delito podría ser tipificado por la autoridad federal. El juez Souter, en su voto particular, en cambio, subraya como este caso afecta a derechos civiles, los cuales habían sido incluidos desde los años sesenta dentro del ámbito protegido por la cláusula de comercio interestatal. Para la mayoría del Tribunal, el Congreso no puede atraer hacia sí la regulación de una materia con el argumento de que se están expandiendo los derechos civiles en nuevas áreas.

Por ahora, no se puede afirmar de forma clara si se trata de un cambio de jurisprudencia o bien estamos ante casos aislados ${ }^{19}$. Habrá que esperar a ver el criterio que siga sobre la cláusula de comercio interestatal el Tribunal Supremo bajo la presidencia de Roberts. De momento, en las escasas ocasiones que ha tenido oportunidad de pronunciarse sobre esta cláusula, Gonzales $v$. Raich ${ }^{20}$, se trataba de un caso referido a actividades tradicionalmente incluidas dentro de dicha competencia porque cumulativamente pueden tener efectos sobre el comercio interestatal. En estga sentencia, el Tribunal ha avalado la constitucionalidad de la ley federal y la inclusión de la misma dentro de los supuestos de la cláusula de comercio interestatal.

\section{LA REVALORIZACIÓN DE LA X ENMIENDA}

Durante la primera parte del siglo xx y hasta 1937, el Tribunal Supremo utilizó la X Enmienda ${ }^{21}$ como canon para anular leyes aprobadas por el Congreso sobre materias de competencia estatal, como era el caso de la legislación sobre limitación del trabajo infantil, o la legislación que preveía subvenciones a la agricultura, o la que imponía un salario mínimo ${ }^{22}$. Según el Tribunal, con estas leyes federales se estaría violando la "soberanía estatal". Se trataba de una aplicación clara del "federalismo dual".

Sin embargo, a partir de finales de los años treinta, la situación cambia y,

19 Un caso en el que sí se aplica la cláusula de comercio interestatal es Pierce County, Wasbington v. Guillen [537 US 129 (2003)] sobre la capacidad del Congreso de legislar acerca de la seguridad en las carreteras (adoptada por unanimidad). En este supuesto se estaría afectando a las vías (channels) para el comercio interestatal.

20545 US 1 (2005), por 6 a 3, se aceptó la constitucionalidad de la ley federal que prohíbe el cultivo y posesión de pequeñas cantidades de marihuana para uso terapéutico, a pesar de que California había autorizado dicha práctica.

21 "Los poderes que la Constitución no delega a los Estados Unidos ni prohíbe a los estados, quedan reservados a los estados y al pueblo respectivamente".

22 Hammer v. Dagenhart, 247 US 251 (1918), United States v. Butler, 297 US 1 (1936), y Carter v. Carter Coal Co., 298 US 238 (1936), respectivamente. A la vez, el Tribunal venía haciendo, en estas sentencias, un uso muy restringido de la cláusula de comercio interestatal, que dejaba fuera de su alcance aspectos como los aquí abordados. 
en el caso United States $v$. Darby citado ${ }^{23}$, el Alto Tribunal llegó a sostener que la X Enmienda contiene un mero "truismo", sin que suponga en ningún caso una cláusula de atribución de competencias exclusivas a los estados, los cuales en consecuencia, quedarían inmunes a la actuación federal. Por tanto, el Tribunal no podría utilizar la X Enmienda para anular leyes federales. No cabe pasar por alto la relación entre este cambio jurisprudencial y la renovación del Tribunal Supremo promovida por el presidente Roosevelt para que avalara la legislación del New Deal, que inicialmente había sido rechazada en sede judicial. Esta nueva doctrina sobre la X Enmienda se mantuvo, casi sin variación, hasta los años noventa. Cuando en 1976 el Tribunal rompió esta línea jusrisprudencial (caso National League of Cities $^{24}$ ), fue un caso excepcional y muy pronto volvió a la doctrina habitual revocando la previa (García v. San Antonio Metropolitan Transit Authority ${ }^{25}$ ).

La doctrina sobre la irrelevancia de la X Enmienda a la hora de limitar la actuación del Congreso duró hasta 1992, en que por vez primera desde que National League of Cities fuese revocada, en New York $v$. United States ${ }^{26}$ el Tribunal anuló una ley federal de 1985 (Low-Level Radioactive Waste Policy Act), que obligaba a los estados a crear depósitos de residuos nucleares seguros para los residuos producidos en el propio estado. Aunque el Tribunal consideró constitucional dicha normativa federal de acuerdo con la cláusula de comercio interestatal, dijo (por 6 a 3) que era contrario a la X Enmienda poner a los estados la disyuntiva de tener que optar entre aceptar la propiedad de los residuos no eliminados a una determinada fecha (y asumir la responsabilidad sobre los perjuicios causados) o regular de acuerdo con las indicaciones del Congreso. Según la juez O'Connor, ello supondría imponer a los estados una obligación de regulación. En opinión del Tribunal Supremo, no se puede obligar a los estados a aprobar normas o ejecutar un programa federal.

23312 US 667 (1941). En esta sentencia, el Tribunal justificó que el Congreso legislara sobre derecho del trabajo, y se impusiera a los estados.

24426 US 833 (1976). En este caso, el Tribunal consideró que la ley federal que imponía a los estados y entes locales la obligación de pagar a sus funcionarios un salario mínimo era inconstitucional, porque afectaba a un ámbito de competencia "tradicional" o "exclusiva" (integral") de los estados.

25469 US 528 (1985). El juez Blackmun sostiene que no es posible determinar cuáles son las actividades exclusivas de los estados sobre las que el Congreso no puede entrar a legislar. Lo más destacado de esta sentencia es que considera que los estados ya participan en el proceso decisorio en el plano federal con lo que ya queda garantizada la presencia de los intereses estatales en dicho plano. A esto sirve precisamente el Federalismo. De este modo, el Tribunal hacía suya la doctrina Weschler-Choper, cuyos autores en sendos artículos ya clásicos de 1954 (H. WESCHLER, "The political safeguards of Federalism", Columbia Law Review, núm. 54, pág. 543 ss) y 1980 (H. CHOPER, Judicial Review and the National Political Process, University of Chicago Press, Chicago) habían sostenido que la delimitación competencial entre la Federación y los estados debe corresponder al Congreso y al Presidente, y no a los tribunales de justicia federales o estatales. Para dichos autores, en la medida en que los estados ya participan en la adopción de decisiones federales en el seno de las instituciones federales, particularmente en el senado, no se necesita la protección judicial de los intereses y las competencias estatales.

26505 US 144 (1992). 
Desde entonces, el Tribunal ha acogido las demandas de los estados contra leyes federales que fuerzan a los estados a legislar o ejecutar en materias de competencia estatal. En Printz v.United States ${ }^{27}$ el Tribunal sostuvo que el Congreso no puede soslayar la prohibición de obligar a los estados a adoptar o ejecutar una determinada regulación federal imponiendo dicha obligación de forma directa a los funcionarios estatales o locales, en lugar de hacerlo a los estados. Se estaría vulnerando, en dicho supuesto, el principio de "dual sovereignty".

\section{LA DOCTRINA DE LA INMUNIDAD DE LOS ESTADOS: LA EXPANSIÓN DE LA XI ENMIENDA Y LA RESTRICTIVA APLICACIÓN DEL APARTADO 5 DE LA XIV ENMIENDA}

En relación con la limitación de la competencia de los tribunales federales con apoyo en el principio federal, el Tribunal Supremo dictaminó que la XI Enmienda ${ }^{28}$ excluye recursos contra las autoridades estatales ante los tribunales federales ${ }^{29}$. El texto de la enmienda se refiere literalmente a la inadmisión de recursos ante tribunales federales contra los estados por parte de ciudadanos de otros estados así como de estados extranjeros ${ }^{30}$. El Tribunal Supremo ha ido más allá de lo dispuesto en la enmienda, al considerar que tampoco caben recursos contra el estado de parte de los ciudadanos del mismo estado, con el fin de preservar de este modo la "inmunidad de los estados ${ }^{31}$, lo que va más allá de la literalidad del precepto, pero se justificaría en el mismo federalismo derivado de la Constitución.

Relevante es el caso Seminole Tribe of Florida $v$. Florida ${ }^{32}$ donde se sos-

27521 US 898 (1997). Por 5 a 4, el Tribunal estimó que era inconstitucional que una ley federal (Brady Handgun Violence Prevention Act) requiriese al funcionario responsable de aplicar la ley en cada localidad para que llevara a cabo averiguaciones antes de conceder las licencias de uso de armas de fuego.

28 "No debe interpretarse que el poder judicial de los Estados Unidos se extiende a cualquier litigio de derecho o de equidad que se inicie o prosiga contra uno de los estados por ciudadanos de otro estado o por ciudadanos o súbditos de cualquier Estado extranjero".

29 Pennhurst State School and Hosp. v. Halderman, 465 US 89 (1984), y Welch v. State Department of Highways and Public Transportation, 483 US 468 (1987). En la primera se sostiene que los funcionarios estatales no pueden ser procesados en tribunales federales respecto a reclamaciones de derecho estatal; en la segunda se afirma que los estados no deben ser obligados a renunciar a su inmunidad. Esta doctrina es subrayada ya por el Tribunal Burger y continuada por el Tribunal Rehnquist. Se ha criticado el objetivo que habría perseguido esta doctrina: impedir que las demandas sobre derechos civiles llegaran a tribunales federales, más proclives que los estatales a su tutela.

30 Crítica esta doctrina E. CHEMERINSKY, Enhancing Government, cit., pág. 145 ss., quien echa de menos que no se requiera el control judicial de la actividad de los poderes estatales.

31 Alden v.Maine, 527 US 706 (1999) donde se indica que no se puede demandar a los estados ante tribunales estatales ni siquiera en relación con pretensiones basadas en la ley federal. Esta sentencia sigue la doctrina del caso Seminole Tribe, que se analizará a continuación.

32517 US 44 (1996) adoptado por 5 a 4. 
tiene que los recursos contra los estados violan la XI Enmienda. Se trata de un recurso contra la Indian Gaming Regulatory Act, donde se indica que los estados deben llegar a acuerdos con las tribus indígenas para permitir el juego en las reservas. En la ley se prevén unos recursos contra los estados ante tribunales federales. Con esta sentencia, se anula un pronunciamiento previo que permitía al Congreso autorizar recursos contra estados ante tribunales federales siempre que se aplicaran leyes federales que los preveían de forma clara y expresa ${ }^{33}$. Así pues, a la vista de la nueva doctrina del Tribunal Supremo, una ley federal que establezca recursos contra estados ante tribunales federales es inconstitucional. La excepción a esta regla se da solo cuando el Congreso actúa con base en el apartado 5 de la XIV Enmienda: entonces sí se puede inaplicar la XI Enmienda.

En relación con la utilización de la XIV Enmienda, la cuestión de la «inmunidad soberana" de los estados aparece también cuando el Tribunal Supremo limita los poderes del Congreso al restringir los objetivos que ha de perseguir el Congreso, de acuerdo con el apartado 5 de la XIV Enmienda ${ }^{34}$. Al hacer esto, se estaba cambiando la línea jurisprudencial anterior que interpretaba de forma expansiva el poder del Congreso, de forma que una ley aprobada por este podía abordar la regulación de cualquier derecho constitucional, estuviera o no comprendido en la XIV Enmienda. Ello en virtud de la doctrina de la "incorporación" creada por el Tribunal Supremo, que amplía el alcance de la cláusula del "due process of law". Esto es precisamente lo que se plantea en City of Boerne v. Flores ${ }^{35}$. Según la sentencia, la ley declarada inconstitucional iba más allá de las competencias que corresponden al Congreso de acuerdo con el apartado 5 de este precepto. Se trata, en definitiva, de ver si el Congreso puede usar sus poderes en relación con esta enmienda para adoptar medidas contra la lesión de derechos constitucionales. El Tribunal optó por limitar el poder del Congreso a la hora de legislar sobre los derechos, puesto que sus poderes en este campo se limitan a proteger los derechos sustantivos del apartado 1 de la XIV Enmienda y porque la Ley de restablecimiento de la libertad religiosa no es congruente ni proporcional con dichos derechos. Por tanto, no cabe alegar dicho precepto para proteger la cláusula de libre ejercicio de la

33 Pennsylvania v. Union Gas Co., 491 US 1 (1989), por 5 a 4.

34 "El Congreso tendrá facultades para hacer cumplir las disposiciones de este artículo por medio de leyes apropiadas".

35521 US 507 (1997) por 8 a 1. Esta sentencia tiene su origen en otra de anterior: Employment Division v. Smith [494 US 872 (1990)], en la que el Tribunal había restringido el ámbito de protección de la cláusula de libre ejercicio de la religión de la I Enmienda, al rechazar una demanda de unos indígenas contra una ley que prohibía el consumo de peyote, a pesar de que se alegara que era una exigencia derivada de su religión. Según el Tribunal, como la ley era neutral y de aplicación general, se puede considerar que no viola la cláusula de libre ejercicio de la religión aunque afecte a prácticas religiosas. En 1993 el presidente Clinton revocó dicha doctrina con la promulgación de la Religious Freedom Restoration Act. Según esta ley, los tribunales tenían que seguir un escrutinio estricto para evaluar las demandas contra la cláusula de libre ejercicio de la religión incluso si se trataba de leyes neutrales. Esta ley fue declarada inconstitucional en City of Boerne. 
religión, u otros derechos constitucionales sustantivos previstos en otros preceptos de la Constitución federal. De este modo, se está protegiendo el federalismo, dejando un margen amplio a la decisión de los estados en materia de derechos constitucionales, tal y como sostuvo el juez Kennedy.

Más tarde, otras sentencias confirmaron la extralimitación del uso que había hecho el Congreso del apartado 5 de la XIV Enmienda, y sostuvo que determinadas leyes aprobadas por el Congreso no podían servir de parámetro para enjuiciar a las autoridades estatales. En Florida Prepaid Postsecundary Education Expense Board v. College Savings Bank ${ }^{36}$, el Tribunal Supremo sostuvo que una ley federal que permitía recursos contra los estados en caso de violación patente de la misma excede del objetivo que el apartado 5 atribuye al Congreso. La ley no es congruente ni proporcional porque no obliga a demostrar la existencia de tal violación por parte de los estados. En Kimel v. Florida Board of Regents ${ }^{37}$, y en University of Alabama v. Garrett ${ }^{38}$, el Tribunal considera que las leyes aprobadas por el Congreso van más allá de lo que prohíbe la Constitución, porque de esta solo se desprende la «igual protección". La ley federal no especifica suficientemente cuando la discriminación por parte de los estados contra los empleados discapacitados es inconstitucional, con base al criterio de proporcionalidad y congruencia. En dichos casos, el Tribunal está ampliando el ámbito de la XI Enmienda para proteger a los estados de demandas ante tribunales federales.

Por último, en Alden v. Maine ${ }^{39}$, el Tribunal declaró que las autoridades estatales no pueden ser demandadas ante tribunales estatales sin el consentimiento del propio Estado, aunque se trate de una pretensión basada en una ley federal. El juez Kennedy, aun admitiendo que la Constitución nada dice sobre la posibilidad de que el Estado litigue en tribunales estatales, considera que sería inconcebible pensar que los estados al ratificar la Constitución hubiesen aceptado someterse a un proceso sin su consentimiento. Ello iría contra la soberanía de los estados. Así, considera que los poderes delegados al Congreso por los estados con base en el art. 1 de la Constitución, no incluyen el poder de juzgar a los estados por demandas privadas ante tribunales estatales. Tampoco pueden ser demandados los estados ante agencias independientes federales, como ocurre en Federal Maritime Comission $v$. South Carolina State Port Authority ${ }^{40}$. En línea con lo sostenido en Alden, el Tribunal considera que la inmunidad de los estados va más allá de la XI Enmienda. Para el Tribunal, el objetivo principal que persigue la inmunidad de los

36527 US 627 (1999).

37528 US 62 (2000). Los gobiernos de los estados no pueden ser demandados por violar la Age Discrimination in Employment Act.

38531 US 356 (2001). Los gobiernos de los estados no pueden ser demandados por violación de la American with Disabilities Act, que prohíbe la discriminación en el trabajo por razón de discapacidad y obliga a los empresarios a llevar a cabo acomodaciones razonables para estos empleados discapacitados.

39527 US 706 (1999) por 5 a 4.

40535 US 743 (2002), por 5 a 4. 
estados es proteger la "dignidad de los gobiernos estatales" y que ello se pondría en cuestión obligando a los estados a intervenir en procedimientos administrativos ante una agencia sin su previo consentimiento.

No podemos concluir este repaso a la jurisprudencia sobre la inmunidad judicial de los estados sin hacer referencia a la más reciente tendencia seguida por el Tribunal Supremo, que parece matizar el alcance de su propia doctrina en este punto. En efecto, el Tribunal ha admitido la legitimidad del Congreso para legislar sobre bajas o permisos médicos o familiares, de acuerdo con el apartado 5 de la XIV Enmienda en Nevada Department of Human Resources $v$. Hibbs ${ }^{41}$. En este caso, evitar la discriminación de la mujer en el trabajo es una finalidad lo suficientemente relevante como para justificar la intervención federal, según el juez Rehnquist. De hecho, el Tribunal Supremo es más exigente con el escrutinio de la discriminación por razón de sexo que la debida a otras causas. Por ello, el Tribunal decidió que la ley federal $\mathbf{F a}$ mily and Medical Leave Act pudiera servir para fundar una demanda contra los gobiernos estatales. También en Tennessee $v$. Lane, el Tribunal Supremo admitió que se pueda demandar a un estado por discriminación contra discapacitados en relación con el derecho de acceso a los tribunales ${ }^{42}$.

También parece que apuntan en la misma dirección los primeros pronunciamientos al respecto del Tribunal Roberts. Así en United States v. Georgia $^{43}$ y en Central Virginia Community College v. Katz ${ }^{44}$. En el primer caso, vuelve a estar en juego la aplicación de la Americans with Disabilities Act y se reconoce al discapacitado - un prisionero que no puede acceder a diferentes servicios - en las instalaciones carcelarias el derecho a recurrir contra el estado invocando la ley federal por la lesión del derecho fundamental a no ser sometido a penas crueles. En el segundo se considera que la inmunidad estatal no debe aplicarse a los procedimientos concursales.

\section{LA DOCTRINA DE LA PREVALENCIA DEL DERECHO FEDERAL SOBRE EL ESTATAL (PREEMPTION)}

De forma, a primera vista, contradictoria con la tendencia a favor de los estados que el Tribunal Supremo ha impregnado al federalismo americano en las últimas dos décadas, el mismo Tribunal ha utilizado, reiteradamente y de

41538 US 721 (2003), por 6 a 3.

42541 US 509 (2004) por 5 a 4 . Se trata de la Americans with Disabilities Act. El Tribunal circunscribe su pronunciamiento favorable a las demandas sobre el derecho de tutela judicial, pero no se pronuncia sobre otras demandas contra los estados respecto a la violación de otros derechos sustantivos de los discapacitados contenidos en la ley federal, que quedan al margen de la XIV Enmienda.

43546 US 151 (2006), por unanimidad.

44546 US 356 (2006), por 5 a 4 . En este caso, que parece revertir la doctrina anterior, el voto que inclinó al Tribunal hacia una postura favorable a la validez de la ley federal correspondió a la juez Sandra Day O'Connor. Como se ha indicado, el juez Alito reemplazó a dicha juez en 2006. 
forma amplia la doctrina, de la primacía o prevalencia del derecho federal sobre el estatal (preemption), que ha servido para limitar las actuaciones de las autoridades estatales y locales. De este modo, una amplia aplicación de la preemption federal tiene como consecuencia acotar la regulación por parte de los estados o una prohibición de adopción de medidas estatales más estrictas que las federales en materias como derecho de daños o de contratos. Por eso se ha dicho que una expansión de la doctrina judicial sobre primacía federal tiene efectos favorables a los intereses de las grandes empresas y contrarios al federalismo, puesto que limita la función de los estados como "laboratorios de democracia". También es cierto que una regulación unitaria de ámbito nacional es defendida por consumidores y otros sectores económicos frente a la pluralidad de regulaciones en una misma materia, que tienden a romper la unidad de mercado ${ }^{45}$. Dicha doctrina es consecuencia de la cláusula de supremacía del derecho federal del art. VI.2 de la Constitución de Estados Unidos ${ }^{46}$.

La utilización judicial de la preemption ha ido cambiando a lo largo del tiempo. Con anterioridad al New Deal, se partía de la idea de competencias exclusivas de la Federación y los estados respectivamente (dual federalism), por lo que se aplicaba la cláusula de primacía federal cuando el Congreso ejercía sus competencias con base en la cláusula de comercio interestatal respecto a toda regulación estatal que entrara dentro de los objetivos de una ley federal. Con el New Deal y la expansión de las competencias concurrentes entre Federación y estados, cambió la doctrina sobre la primacía, dando paso a la Modern preemption. Con ella se trataba de poner freno a la utilización expansiva y centralizadora que desde entonces se va a dar a la cláusula de comercio interesstatal: de entrada, cuando el Congreso prevé expresamente la primacía sobre leyes estatales, en cambio, el derecho federal prevalece sobre el estatal. Más problemática resulta la aplicación de la citada doctrina en ausencia de previsión normativa clara, de manera implícita. En tal caso, el Tribunal distingue tres hipótesis en las que operaría la prevalencia federal sobre las normas estatales: a) cuando la legislación federal es tan exhaustiva que no deja espacio para ser complementada por la regulación estatal (field preemption); b) cuando hay un conflicto insalvable entre los contenidos de la norma federal y los de la estatal que no permite la aplicación simultánea de ambas (conflict preemption); y c) cuando la ley estatal impide el entero cumplimiento de los objetivos de la legislación federal ${ }^{47}$. Más allá de tales supues-

45 Así R. FALLON, "Conservative Paths of the Rehnquist Court's Federalism Decisions", University of Chicago Law Review, núm. 429, 2002. En igual sentido, E. CHEMERINSKY, Enhancing Government, cit. págs. 227 y 240. La justificación conservadora de la utilización de esta doctrina viene por su tendencia desreguladora. Así en R. A. EPSTEIN y M. S. GRAVE (Ed.), Federal Preemption: States' Powers, National Interests, AEI, Washington, 2007.

46 "Esta Constitución, y las leyes de los Estados Unidos que se expidan con arreglo a ella, y todos los tratados celebrados o que se celebren bajo la autoridad de los Estados Unidos, serán la suprema ley del país; y los jueces de cada Estado están obligados a observarlos, a pesar de cualquier cosa en contrario que se encuentre en la Constitución o las leyes de cualquier Estado".

47 Se contiene el test sobre la preemption en Gade v. National Solid Waste Management Association, 505 US 88 (1992). 
tos, se solía partir de una presunción a favor de los estados y de no aplicación de la prevalencia de la ley federal si se trataba de ámbitos en los que los estados ejercían tradicionalmente sus competencias. En tal caso operaba la presunción de que los poderes del estado no habían de ser reemplazados por el Congreso salvo declaración expresa de este ${ }^{48}$.

En los últimos tiempos, y coincidiendo con el replanteamiento de la cláusula de comercio interestatal, el Tribunal Supremo ha empleado la preemption contra leyes estatales de forma abundante, yendo más allá de las previsiones expresas del Congreso acerca de la primacía de las leyes federales sobre el derecho estatal, e incluso respecto a normas sobre materias de competencia exclusiva de los estados. En este caso, existe una clara correspondencia entre ese uso activo por parte del Tribunal y el considerable volumen de leyes aprobadas por el Congreso desde 1970 que incorporan la preemption ${ }^{49}$. Como casos destacados de esta nueva etapa en el empleo de la preemption merecen destacarse los casos Geier v. American Honda Motor Co. Inc...$^{50}$, Crosby v. National Foreign Trade Counci ${ }^{1}$, Lorillard Tobacco Co. v. Reilly ${ }^{52}$, y American Insurance Association v. Garamendi ${ }^{53}$. En dichas sentencias, la mayoría conservadora del Tribunal abandona la línea jurisprudencial anterior, mientras que los votos particulares de los jueces de la minoría resaltan que con dichas sentencias se está reduciendo la autonomía normativa de los estados.

Últimamente, el Congreso ha recurrido a la preemption para justificar la necesidad de proteger un interés nacional en casos de situaciones de emergencia o de catástrofe ${ }^{54}$. Y el Tribunal Supremo ha recurrido a ella para evitar

48 Así por ejemplo en Hillsborough County, Florida v. Automated Medical Laboratories Inc., 471 US 707 (1985).

49 J. KINCAID, "Contemporary U.S. Federalism: Coercive change with Cooperative continuity", Revista d'Estudis Autonòmics i Federals, núm. 6, 2008, pág. 14. Si entre 1789 y 1969 el Congreso aprobó 200 preemptions, entre 1970 y 2004 fueron 320. El autor incluye dicha doctrina dentro del federalismo coercitivo que caracteriza el americano desde los años treinta del s. xx..

50529 US 861 (2000), el Tribunal considera que hay una conflict preemption y que no cabe un recurso estatal planteado por una víctima de accidente dirigido a exigir la responsabilidad por daños causados por vehículos que no cumplan los estándares de seguridad, aun cuando la ley federal no excluyera tal recurso.

51530 US 363 (2000), el Tribunal invalida una ley de Massachussets que prohibía al Estado comprar bienes y servicios a compañías que hicieran negocios con Birmania, dadas las violaciones de derechos en dicho país. Unánimemente el Tribunal considera que el Congreso ya ha adoptado sanciones contra Birmania y se estsá interfiriendo en las relaciones internacionales, que son competencia de la Federación.

52533 US 525 (2001), por 5 a 4, el Tribunal consideró que la ley federal prevalece sobre la estatal de Massachussets que prohibía poner anuncios publicitarios sobre cigarrillos en espacios públicos cerca de parques y escuelas, para proteger a los niños.

53539 US 396 (2003), por 5 a 4, se declara prevalente la política exterior federal (ninguna ley en concreto) sobre una ley de California que requería a las compañías de seguros que hicieran negocio en el Estado que revelaran su política de seguros durante la época del Holocausto en Europa.

54 Así, el Congreso la ha utilizado en la National Defense Autborization Act de 2006, que habilita al Presidente para asumir el mando (y por tanto federalizar) de la Guardia Nacional de cada Estado, cuyo mando corresponde a su Gobernador, aun sin el consentimiento de este, en 
la maniobra llevada a cabo por jueces estatales consistente en permitir nuevas class actions con la misma pretensión que otras prohibidas por el Congreso, y, de este modo, sortear la prohibición de la ley federal ${ }^{55}$; asimismo el Tribunal la ha aplicado a recursos estatales en relación con derecho de daños ${ }^{56}$. Por último, cabe recordar como la anulación de la ley de California que permitía el uso terapéutico de la marihuana, realizada en Gonzalez $v$. Raich, supone un intento de evitar la regulación estatal en este punto y el Tribunal utilizó la preemption del derecho federal ${ }^{57}$.

\section{PERSPECTIVAS DE FUTURO}

Los estudiosos que se han acercado a la última evolución del federalismo americano han constatado el profundo cambio producido en la jurisprudencia del Tribunal Supremo, sobre todo a partir de los años noventa del siglo $\mathrm{XX}$, bajo la presidencia de William Rehnquist. Así, hemos visto como el Tribunal, por vez primera desde hacía sesenta años, ha declarado inconstitucional una ley federal por vulnerar la cláusula de comercio interestatal (en Lopez y en Morrison); ha considerado que la X Enmienda actúa como límite el poder del Congreso, en favor de los estados, anulando otras leyes federales por violación de dicha enmienda (en New York y en Printz); ha circunscrito el poder del Congreso que le otorga el apartado 5 de la XIV Enmienda en relación con los derechos constitucionales (de nuevo en Lopez y en City of Boerne); y ha ampliado la zona de inmunidad soberana de los estados al desestimar que estos tengan que litigar ante tribunales federales ni estatales por vulneración de leyes federales (en Seminole Tribe y en Alden). De este modo, en nombre del federalismo, se ha limitado de forma severa tanto las competencias federales del Congreso como el ámbito de la jurisdicción de los tribunales federales ${ }^{58}$. La excepción a esta línea dominante la ofrece la expansiva aplicación de la doctrina de la preemption (en Greier, en Crosby, en Lorillard Tobacco Co. y en Garamendi).

Sin embargo, no todos los autores coinciden a la hora de predicar la continuidad actual o no de esta "revolución federal". Mientras Chemerisnky

caso de catástrofe o grave accidente natural o humano. Esta ley se aprobó como consecuencia de la gestión del huracán Katrina en Nueva Orleans en 2005.

55 Merril Lynch v. Dabit, 547 US 71 (2006). Unánimemente adoptada.

56 United States $v$. Locke, 529 US 89 (2000).

57545 US 1 (2005).

58 D. L. SHAPIRO, Federalism: a Dialogue, Northwestern University Press, Evanston, 1995, pág. 111 ss y epílogo, subraya la relevancia de New York v. United States y de United States $v$. Lopez para la limitación, por parte del poder judicial, del poder del Congreso en uso de la X Enmienda y de la cláusula de comercio interestatal respectivamente. Sin embargo, el profesor Shapiro ya advierte justo al comienzo de la etapa del federalismo americano aquí estudiada, que el verdadero genio del federalismo americano reside en su tendencia permanente y constitucionalmente asegurada al diálogo en el plano político sobre el adecuado equilibrio entre la demanda de centralización y las virtudes de la dispersión del poder (pág. 140). 
advierte el mantenimiento de la misma, Kincaid le pone fecha de clausura: 2002, y, desde entonces se habría vuelto al federalismo coercitivo, con elementos tanto de federalismo cooperativo como dual ${ }^{59}$.

Antes de concluir nos podemos preguntar por la tendencia de futuro que se vislumbra en relación con el federalismo en Estados Unidos, a partir de la consideración de determinados sucesos de diferente orden que pueden condicionar su evolución próxima. Nos referiremos en concreto a la influencia que, en el debate sobre el federalismo, ha tenido la gestión del huracán Katrina; a los cambios en la composición del Tribunal Supremo tras los últimos nombramientos producidos desde 2005 con la retirada del presidente Rehnquist; a la elección del presidente Obama en noviembre de 2008 en un contexto de nuevas mayorías demócratas en ambas Cámaras del Congreso; y, en último término, a la reacción republicana contra las primeras medidas económicas del nuevo presidente, con la invocación, de nuevo, de la cuestión federal.

El huracán Katrina, que destrozó Nueva Orleans a finales de agosto de 2005, y la gestión política del desastre natural ha motivado una serie de reflexiones doctrinales (y políticas) entorno a la capacidad de un sistema como el americano, basado en la división vertical de poderes públicos, para afrontar con éxito situaciones de crisis tan graves y en los cambios que ha de sufrir el federalismo para mejorar la capacidad de respuesta. Se ha constatado que el huracán puso a prueba el funcionamiento coordinado de las instituciones de gobierno federales, estatales y locales. Ello ha llevado a sostener que el sistema federal, con la consiguiente división de responsabilidades, fue un obstáculo para la gestión de la crisis, así como para la reconstrucción ulterior de las zonas afectadas, como había influido en las causas del desastre. En el Informe elaborado por un Select Committee de la Cámara de Representantes, nombrado para investigar la responsabilidad de las autoridades federales ante el suceso, se puso de manifiesto que intervinieron múltiples departamentos y agencias de los diferentes niveles de gobierno, los cuales tenían algún tipo de competencia en el suceso, pero sin coordinarse suficientemente ${ }^{60}$. Así, una de las primeras conclusiones del Informe que se acaba de citar es que se trató de una crisis de dimensión nacional. Parte del problema consistió en que había fallado la comunicación entre las autoridades estatales y locales a la hora de planear y organizar las respuestas institucionales efectivas, y no que se hubiese tratado de un problema de falta de recursos federales.

59 E. CHEMERINSKY, Enhancing Government, cit.; J. KINCAID, "Contemporary U.S. Federalism: Coercive change with Cooperative continuity", cit., pág. 19. También sostiene la vuelta al federalismo coercitivo, P. POSNER, "The politics of coercitive federalism in the Bush era", Publius, núm. 37, 2007, pág. 17.

60 US House of Representatives, "A Failure of Initiative: Final Report of the Select Bipartisan Committee to investigate the preparation for and response to Hurricane Katrina", febrero 2006, en http://katrina.house.gov/; y también el Informe de la Casa Blanca, "The federal Response to Hurrican Katrina: Lessons Learned", febrero 2006. Ver http://georgewbush-whitehouse.archives. gov/reports/katrina-lessons-learned/ 
A partir de esta situación dada, se abrió en Estados Unidos un debate académico y en los medios de comunicación sobre la pretendida responsabilidad del federalismo en este tipo de sucesos. Para unos, la distribución de competencias está hecha, en principio, de modo que las competencias para afrontar los desastres deben corresponder a las autoridades federales por ser las que conocer mejor cómo hacer frente a una crisis de esta magnitud. Por tanto, la salida ante una situación crítica como la descrita pasaría por incrementar la coordinación intergubernamental y por que el Gobierno nacional asuma la dirección política ante sucesos de este género. Esto conlleva un replanteamiento del modelo federal, pues este tipo de situaciones de emergencia no están presentes entre los objetivos primeros del federalismo al inicio del Pacto federal y que, aunque ya se plantearon durante los años treinta del siglo XX con ocasión del New Deal, no se tradujo en ninguna reforma constitucional. Por esto, de forma gráfica, el profesor Griffin ha llegado a afirmar, como título de un artículo doctrinal dedicado al tema, que hay que "parar el federalismo antes que el federalismo nos mate de nuevo" ${ }^{61}$. En cambio, otros autores han criticado las conclusiones de este análisis, señalando que lo que falló en Katrina no fue el federalismo sino la concreta forma de federalismo basada en la excesiva centralización o dirección de la política de seguridad interior por parte del gobierno federal, y en su descoordinación con las autoridades estatales y locales, que son las competentes para elaborar planes para afrontar tales situaciones. La salida entonces pasa más bien por reforzar la cooperación en un plano de igualdad entre los distintos niveles de gobierno, y por primar el conocimiento y la cercanía a los problemas que tienen las autoridades locales y estatales ${ }^{62}$. Por ahora, la llamada a una mayor centralización ha hallado respuesta, como ya hemos visto al final del apartado anterior, en el plano legislativo federal, al aprobar el Congreso una ley que permite al Presidente tomar el control de la Guardia Nacional de un estado en casos de desastre natural u otras catástrofes.

Respecto a la jurisprudencia del Tribunal Supremo, en principio nada parece indicar que el Tribunal Roberts vaya a alterar la concepción del federalismo predominante bajo la presidencia Rehnquist. El equilibrio entre mayoría conservadora y minoría liberal en la composición del Tribunal no se ha visto alterada tras la designación, durante el segundo mandato del presidente Bush, de los jueces Roberts y Alito en lugar de otros dos jueces conservadores, ni con el nombramiento por el presidente Obama en 2009 de la juez Sotomayor, pues substituye al juez Souter, el cual aunque hubiese sido nombrado por el presidente Bush (padre), desde muy pronto se alineó con los jueces liberal. En cualquier caso, estamos, como se ha visto, ante un Tribunal

61 S. M. GRIFFIN, "Stop federalism before it kills again: reflections on Hurricane Katrina", Saint John Journal of Legal Commentary, núm. 21, 2007, pág. 527 ss.

62 Th. BIRKLAND y S. WATERMAN, "Is federalism the reason for policy failure in Hurricane Katrina?", Publius, núm. 38, 2008, pág. 15; y Ch. E. WELLS, "Katrina and the Rethoric of federalism", Mississippi College Law Review, núm. 26, 2006-7, pág. 127 ss. Para esta autora, el problema no está en el federalismo coorperativo sino en la implementación del mismo al caso concreto. 
profundamente dividido, como atestiguan las ajustadas mayorías (5-4) con las que han salido a delante buena parte de las sentencias más controvertidas a la vez que relevantes para el éxito de la denominada Revolución federal. Habrá que ver, no obstante, si algunas de las correcciones introducidas a la jurisprudencia más pro estados en los últimos años se mantienen o no en el futuro inmediato. Y si los jueces adoptan una actitud más activista o más respetuosa con la actuación del Congreso (federal). Por ahora, no ha habido grandes ocasiones para que el Tribunal pudiera demostrar ni una cosa ni la otra.

Más incógnitas plantea, respecto a los temas federales, la posición del nuevo Congreso, con mayoría demócrata en ambas cámaras, y del presidente Obama. En el primer año de la presidencia Obama (como había ocurrido durante la campaña electoral) el tema del federalismo ha ocupado un lugar secundario en la agenda política, dada la situación de grave crisis económica a la que ha debido hacer frente y al plan de estímulo económico aprobado por el Congreso así como otras opciones legislativas prioritarias, como la reforma del sistema sanitario. Otra cosa es que dichas políticas no tengan incidencia sobre el federalismo y la posición de los estados. De hecho, al comienzo de la Administración Obama se habló de avanzar hacia una nueva etapa de relaciones Federación-estados, denominada "progressive federalism", con consecuencias respecto a iniciativas medioambientales, y protección de los consumidores entre otros temas ${ }^{63}$. En este sentido, se destaca una decisión temprana del presidente Obama de permitir a California y a otros estados que establezcan sus propios límites a la emisión de gases de efecto invernadero por los vehículos de motor. Se trataría de reforzar el federalismo cooperativo de forma que Federación y estados trabajen conjuntamente para la realización de objetivos nacionales, al tiempo que se reforzaría la intervención pública gubernamental. Frente al impulso dado por las administraciones anteriores a la preemption federal, ahora se pretendería valorar el papel que pueden desempeñar los estados como "laboratorios de democracia" en materias sociales y económicas, que complementen y puedan ejecutar la legislación federal. En definitiva, un tipo de federalismo que ponga el énfasis en fortalecer a los órganos de gobierno - federal, pero también estatales- en lugar de la visión defensiva del federalismo con predominio del poder judicial, como hasta ahora ha predominado.

Por último, cabe destacar que, frente a las principales líneas de actuación política emprendidas por el presidente Obama, los republicanos han empezado a dar la batalla, en no pequeña medida, desde los estados y utilizando, como otras veces en la historia constitucional americana, el argumento de que con ello se estaría avanzando hacia el centralismo (y el intervencionismo público). En este contexto, se entienden las resoluciones (sin valor vinculante) que han aprobado las Asambleas legislativas de ya más de una veintena

63 J. SCHWARTZ, "Obama seems open to a broader role for States", New York Times, 30 enero 2009. 
de estados en que se recuerda la vigencia de la X Enmienda, el poder soberano de los estados, y el carácter limitado del poder central como respuesta a las medidas adoptadas en Washington por el Gobierno Federal ${ }^{64}$.

Las elecciones de noviembre de 2010 significarán un momento crucial para apreciar el rol que va a tener el federalismo en la segunda mitad de la Administración Obama. El precedente es claro: la mayoría republicana en el Congreso en 1994, a los dos años de la victoria del presidente Clinton, significó un claro empuje en la defensa de los derechos de los estados tanto en el Legislativo como en el Judicial.

TiтLE: Supreme Court and changes in the Federalism of the United States.

ABSTRACT: The article analyzes the new US Federalism approach assumed during the last two decades by the Rehnquist's Court. The Supreme Court defends a restrictive interpretation of the powers of the Congress (interstate commerce clause, Section 5 of the Fourteenth Amendment and with the Tenth Amendment). At the same time, the Supreme Court uses widely the preemption doctrine. It is soon to announce the continuation or not of this Federalism Revolution, but it seems that the current Roberts's Court substantially follows Rehnquist's doctrine, and Obama's Administration is in favor of a "progressive Federalism" with a more cooperation between Central and States' authorities.

RESUMEN: El artículo pasa revista a la revalorización del federalismo americano a lo largo de las dos últimas décadas que ha llevado a cabo el Tribunal Supremo bajo la presidencia del juez Rebnquist. El Tribunal aboga por una interpretación restrictiva de los poderes del Congreso (cláusula de comercio interestatal, apartado 5 de la XIV Enmienda, y a través de la X Enmienda). Sin embargo, al mismo tiempo utiliza de forma amplia la doctrina de la primacía del derecho federal sobre el estatal. Aunque sea pronto para advertirlo, parece que el nuevo Tribunal Roberts sigue sustancialmente la doctrina precedente y que la presidencia Obama apunte a un "federalismo progresivo" en el que prime la cooperación entre las autoridades centrales y estatales.

KeY words: Federalism. States' Rights. Supreme Court.

Palabras clave: Federalismo. Poderes de los estados. Tribunal Supremo.

64 http://www.tenthamendmentcenter.com/. Consultado por última vez el 1 de octubre de 2009. Según los datos del Tenth Amendment Center, 18 Estados han adoptado definitivamente esta resolución, en otros 9 la ha votado una de las dos cámaras legislativas, en otros 6 las dos y en 1 se ha rechazado. 